\title{
$\beta 1$ Integrin as a Prognostic and Predictive Marker in Triple-Negative Breast Cancer
}

\author{
Hsin-Ling Yin ${ }^{1,2}$, Chun-Chieh Wu ${ }^{1}$, Chih-Hung Lin ${ }^{1}$, Chee-Yin Chai ${ }^{1,2,3}$, Ming-Feng Hou ${ }^{3,4,5}$, \\ Shu-Jyuan Chang ${ }^{3}$, Hung-Pei Tsai ${ }^{3}$, Wen-Chun Hung ${ }^{4,6}$, Mei-Ren Pan ${ }^{4,5,7, *}$ \\ and Chi-Wen Luo 1,4,* \\ 1 Department of Pathology, Kaohsiung Medical University Hospital, Kaohsiung Medical University, \\ 807 Kaohsiung, Taiwan; fp7081@gmail.com (H.-L.Y.); lazzz_wu@yahoo.com.tw (C.-C.W.); \\ chlathelas@gmail.com (C.-H.L.); cychai@kmu.edu.tw (C.-Y.C.) \\ 2 Department of Pathology, Faculty of Medicine, Collage of Medicine, Kaohsiung Medical University, \\ 807 Kaohsiung, Taiwan \\ 3 Graduate Institute of Medicine, College of Medicine, Kaohsiung Medical University, 807 Kaohsiung, Taiwan; \\ mifeho@kmu.edu.tw (M.-F.H.); binbin4728@hotmail.com (S.-J.C.); carbugino@gmail.com (H.-P.T.) \\ 4 Cancer Center, Kaohsiung Medical University Hospital, 807 Kaohsiung, Taiwan; hung1228@nhri.org.tw \\ 5 Graduate Institute of Clinical Medicine, Kaohsiung Medical University, 807 Kaohsiung, Taiwan \\ 6 National Institute of Cancer Research, National Health Research Institutes, 704 Tainan, Taiwan \\ 7 Research Center for Environmental Medicine, Kaohsiung Medical University, 807 Kaohsiung, Taiwan \\ * Correspondence: mrpan@cc.kmu.edu.tw (M.-R.P.); 1040141@kmuh.org.tw (C.-W.L.); \\ Tel.: +886-7-312-1101 (ext. 7081) (C.-W.L.); Fax: +886-7-313-6681 (C.-W.L.)
}

Academic Editors: Anthony Lemarié and Sylvie Monferran

Received: 20 July 2016; Accepted: 23 August 2016; Published: 31 August 2016

\begin{abstract}
Triple negative breast cancer (TNBC) displays higher risk of recurrence and distant metastasis. Due to absence of estrogen receptor (ER), progesterone receptor (PR) and human epidermal growth factor receptor 2 (HER2), TNBC lacks clinically established targeted therapies. Therefore, understanding of the mechanism underlying the aggressive behaviors of TNBC is required for the design of individualized strategies and the elongation of overall survival duration. Here, we supported a positive correlation between $\beta 1$ integrin and malignant behaviors such as cell migration, invasion, and drug resistance. We found that silencing of $\beta 1$ integrin inhibited cell migration, invasion, and increased the sensitivity to anti-cancer drug. In contrast, activation of $\beta 1$ integrin increased cell migration, invasion, and decreased the sensitivity to anti-cancer drug. Furthermore, we found that silencing of $\beta 1$ integrin abolished Focal adhesion kinese (FAK) mediated cell survival. Overexpression of FAK could restore cisplatin-induced apoptosis in $\beta 1$ integrin-depleted cells. Consistent to in vitro data, $\beta 1$ integrin expression was also positively correlated with FAK $(p=0.031)$ in clinical tissue. More importantly, $\beta 1$ integrin expression was significantly correlated with patient outcome. In summary, our study indicated that $\beta 1$ integrin could regulate TNBC cells migration, invasion, drug sensitivity, and be a potential prognostic biomarker in TNBC patient survival.
\end{abstract}

Keywords: Triple negative breast cancer; $\beta 1$ integrin; migration; invasion; drug sensitivity

\section{Introduction}

Triple negative breast cancer (TNBC) is a specific breast cancer subtype that is immunohistochemically negative for expressions of prognostic markers including estrogen receptor (ER), progesterone receptor (PR), and human epidermal growth factor receptor 2 (HER2) [1]. TNBC accounts for $10 \%-20 \%$ of all breast cancers, more frequently arises in younger patients, and is more prevalent in African-American women [2]. Compared to other breast tumors, TNBC tumors are generally more aggressive and have larger size and higher grade [3]. Additionally, TNBC patients often 
present with early distant metastases and lymph node involvement at the time of diagnosis $[3,4]$. This aggressive metastatic phenomenon contributes to short overall survival in patients with TNBC $[5,6]$. Paradoxically, despite TNBC patients having higher response rates to presurgical (neoadjuvant) chemotherapy, these patients still have higher rates of distant metastasis and poorer prognosis than do patients with other breast cancer subtypes [3,7]. The dissemination of cancer cells from the primary tumor to a distant organ is the most common cause of death for patients with cancer [8]. Therefore, how to decrease the rate of metastasis in TNBC patients is an important issue.

Integrins, which are transmembrane receptors in a large family of $18 \alpha$ and $8 \beta$ heterodimeric transmembrane proteins, were well known as adhesion molecules in mediating cell-extracellular matrix (ECM) interaction [9]. Integrins are important sensors of the cell microenvironment and regulate many intracellular and extracellular signaling pathways involving the organization of cells, tissues and organs during development in response to structural variations of the extracellular matrix. Integrins have been implicated in many processes associated with tumor cell adhesion to the extracellular matrix (ECM), including migration, invasion, and metastasis [10-12]. Integrins also play significant roles in regulating cell apoptosis-associated gene expression [13]. Because of their critical roles in many cellular processes that are hallmarks of cancer development, integrins are also important therapeutic targets [14].

Recent attention has been focused on the role of $\beta 1$ integrin in malignant phenotype [15]. Previous studies have indicated that $\beta 1$ integrin is an important integrin expressed in normal cells and in tumor-associated cells since it controls various development processes [16-23]. Other studies also show that, in many cancer types, $\beta 1$ integrin might induce resistance to radiotherapies, chemotherapies, and target therapies [24-28]. Noted, several $\beta 1$ integrin antagonists also have been studied in recent years $[29,30]$. Based on these findings, $\beta 1$ integrin could be applied to several types of cancers including breast cancer [31]. However, whether $\beta 1$ integrin plays an important role in mediating the migration and invasion capacities and drug resistance in TNBC cells is still unclear. In current study, we investigated the roles of $\beta 1$ integrin in three TNBC cells (MDA-MB-231, HS-578T, and MDA-MB-468) and TNBC patients. Our results indicated that $\beta 1$ integrin could regulate the migration, invasion, and epithelial-mesenchymal transition (EMT) in TNBC cells. The survival rates of cells after cisplatin treatment were clearly decreased in $\beta 1$ integrin knockdown cells but restored in $\beta 1$ integrin-activating cells. Clinical analyses also showed that $\beta 1$ integrin was related to metastasis, recurrence, and survival in TNBC patients. Thus, our study provides convincing evidence that $\beta 1$ integrin is a potential prognostic biomarker for TNBC patients.

\section{Results}

\subsection{Expression of $\beta 1$ Integrin in Normal Mammary Epithelial Cells and Triple Negative Breast Cancer (TNBC) Cells}

To analyze the role of $\beta 1$ integrin on TNBC cells, we first compared the basal expression of $\beta 1$ integrin in normal human mammary epithelial cell (M10) and three TNBC cells (MDA-MB-231, MDA-MB-468 and HS578T). Figure 1 shows the immunoblot results, which indicated that MDA-MB-231 and HS578T cells had higher expression of $\beta 1$ integrin compared to M10 and MDA-MB-468 cells. In this series of experiments, MDA-MB-231 and HS578T cells were transfected with short interfering Control (wild type, WT) and $\beta 1$ integrin silencing (KO), and MDA-MB-468 was incubated with mouse IgG1 negative control (wild type, WT) and $\beta 1$ integrin activator (MAB). 


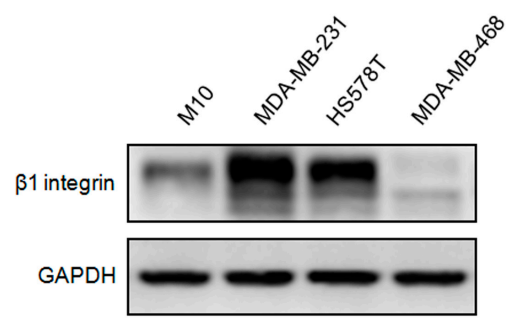

Figure 1. Comparison of $\beta 1$ integrin expression between normal and Triple negative breast cancer (TNBC) cells. Expression of $\beta 1$ integrin was compared in normal human mammary epithelial cell (M10) and three TNBC cell lines (MDA-MB-231, HS578T and MDA-MB-468). Cell lysates were immunoblotted by anti- $\beta 1$ integrin. Glyceraldhyde-3-phosphate dehydrogenase (GAPDH) was used as a loading control. The experiments were performed independently at least three times.

\section{2. $\beta 1$ Integrin Affected TNBC Cell Migration and Invasion}

The effects of $\beta 1$ integrin on TNBC cells motility were investigated by using a standard wound-healing assay. As shown in Figure 2A, knockdown of $\beta 1$ integrin significantly led to the reduction of migration in MDA-MB-231 and HS578T cells compared to parental cells. A transwell invasion assay was then used to study invasion ability in both cell lines. As shown in Figure 2B,C, invasion ability was suppressed in $\beta 1$ integrin knockdown cells. In contrast, activation of $\beta 1$ integrin increased migration and invasion in MDA-MB-468 cells (Figure 2A-C). Hence, these results suggested that $\beta 1$ integrin affected the migration and invasion of TNBC cells.

(A)

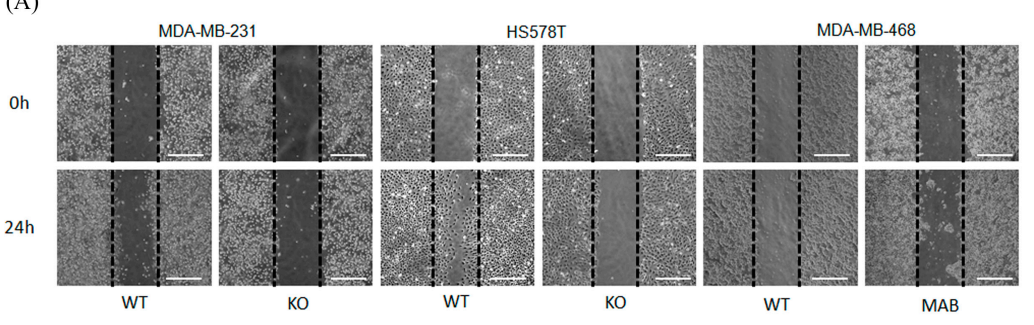

(B)
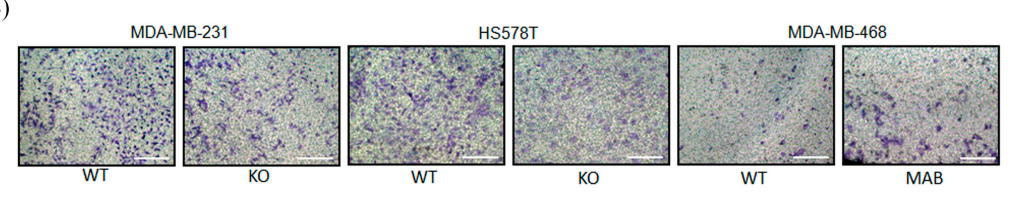

(C)
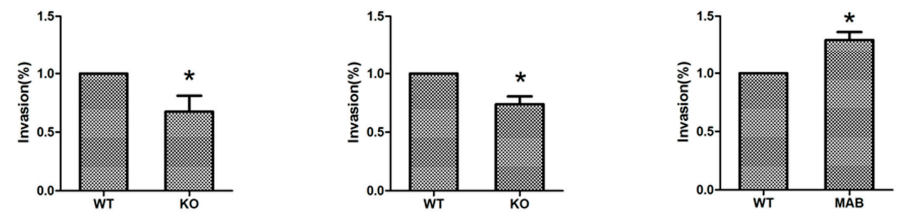

Figure 2. Validation the roles of $\beta 1$ integrin in TNBC cell migration and invasion. (A) Parental (WT) and $\beta 1$ integrin silencing (KO) MDA-MB-231 and HS578T cells, parental (WT) and $\beta 1$ integrin activating (MAB) MDA-MB-468 cell were cultured until reaching $90 \%$ confluence. A scratch was made with pipette in each well. Cell migration was photographed at $0 \mathrm{~h}$ and $24 \mathrm{~h}$. Magnification $\times 200$, scale bar: $100 \mu \mathrm{m}$. The experiments were performed independently for at least three times; (B) MDA-MB-231 and HS578T cells were transfected with control and $\beta 1$ integrin siRNA for $24 \mathrm{~h}$. MDA-MB-468 cell was treated with IgG control and $\beta 1$ integrin activator for $6 \mathrm{~h}$. Cells were analyzed by transwell cell culture chambers after $24 \mathrm{~h}$. Cell invasion was photographed at $24 \mathrm{~h}$. Magnification: $\times 400$, scale bar: $50 \mu \mathrm{m}$; (C) Bar chart showing the quantification of cell invasion by counting the number of cell invade underside of the membrane. Values represent the mean \pm SD from at least 3 experiments. Statistically significant data are indicated by * for significant at $p<0.05$. 
2.3. $\beta 1$ Integrin Regulated Expressions of Proteins Related to the Epithelial-Mesenchymal Transition (EMT) in TNBC Cells

To further verify the role of $\beta 1$ integrin in contributing cell mobility, we next determined the role of $\beta 1$ integrin in the process of EMT. As performed in Figure 3, we found that the depletion of $\beta 1$ integrin decreased a series of EMT-associated proteins including $N$-cadherin, $\beta$-catenin, and vimentin in MDA-MB-231 and HS578T cells. Conversely, activation of $\beta 1$ integrin increased the level of $\beta$-catenin and decreased the level of E-cadherin in MDA-MB-468 cells. These experimental results strongly indicated that levels of $\beta 1$ integrin could alter several proteins related to the EMT in TNBC cells.

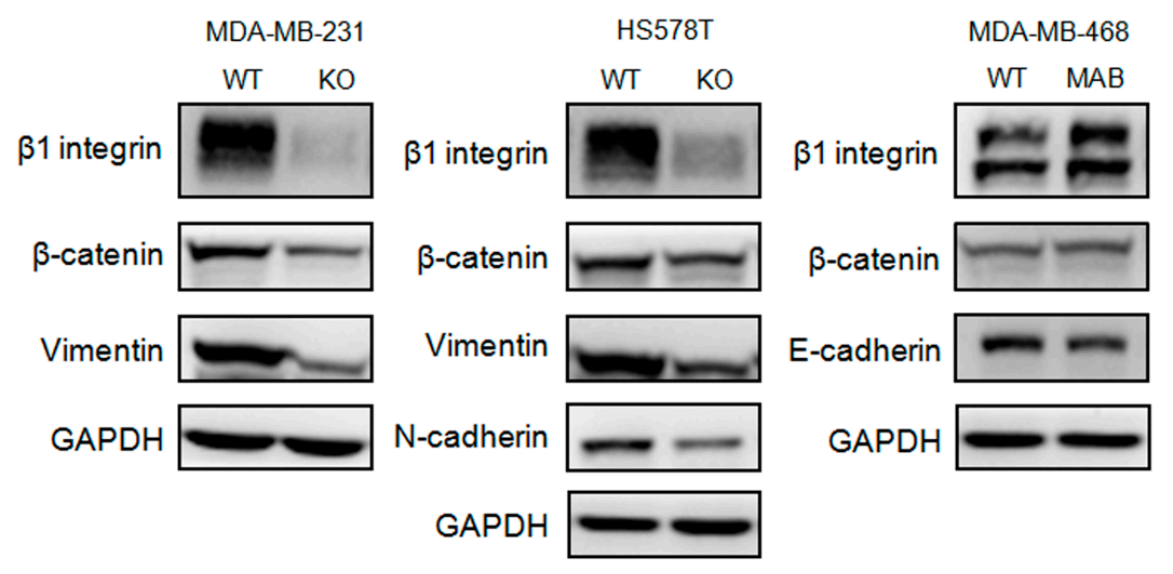

Figure 3. $\beta 1$ integrin regulates the epithelial-mesenchymal transition (EMT) relative protein expressions in TNBC cells. Cell lysates from parental and $\beta 1$ integrin silencing MDA-MB-231 and HS578T cells, and parental and $\beta 1$ integrin activating MDA-MB-468 cell were immunoblotted by anti- $\beta 1$ integrin, anti- $\beta$ catenin, anti-N-cadherin, anti-E-cadherin and anti-Vimentin. GAPDH was used as a loading control. Data were collected in at least three independent experiments.

\subsection{Inhibition of $\beta 1$ Integrin Attenuated Cisplatin-Induced Apoptosis}

In order to further clarify the role of $\beta 1$ integrin in TNBC cells, we next examined if $\beta 1$ integrin plays a regulatory role in the drug sensitivity of TNBC cells. Figure 4A shows the cisplatin sensitivity in three different TNBC cells. MDA-MB-231 and HS578T cells were more resistant to cisplatin than MDA-MB-468 cell. We found that knockdown of $\beta 1$ integrin increased cisplatin sensitivity in MDA-MB-231 and HS578T cells. Conversely, activation of $\beta 1$ integrin can efficiently decrease the toxic effect of cisplatin to MDA-MB-468 cell (Figure 4B). Previous data reported that cisplatin damages tumors via induction of apoptosis. We next determined whether $\beta 1$ integrin played a role in mediating cisplatin-induced apoptosis. Consistent to our hypothesis, knockdown of $\beta 1$ integrin increased cleaved forms of PARP and caspase 3 in both cells, as performed by western blot. It indicated that $\beta 1$ integrin defects triggered the increase of toxic effect of cisplatin via induction of the apoptotic pathway (Figure 4C).

\section{5. $\beta 1$ Integrin Modulates FAK-Mediated Drug Sensitivity and Cell Survival}

To further characterize the details of the mechanism in $\beta 1$ integrin-mediating drug sensitivity, we next sought to identify the downstream signal pathway involved in TNBC. As shown in Figure 5A, knockdown of $\beta 1$ integrin resulted in decreasing phosphorylated levels of FAK and Protein kinase $B$ (Akt) in MDA-MB-231 and HS578T cells, compared to WT cells in our experiments. In addition, ILK and phosphorylated levels of Extracellular signal-regulated kinase (ERK) and GSK3 $\beta$ also decreased after knockdown of $\beta 1$ integrin. In contrast, activation of $\beta 1$ integrin in MDA-MB-468 cells resulted in increasing the levels of phosphorylated FAK, Akt and ERK compared to parental cells (Figure 5A). Importantly, our MTT assay and western blot results indicated that overexpression of FAK could 
dramatically overcome the cisplatin-mediating cytotoxic effect in $\beta 1$ integrin defects cells (Figure $5 B, C$ ). In summary, $\beta 1$ integrin-mediated regulation of FAK-Akt signals in contributing drug sensitivity and migration ability.

(A)

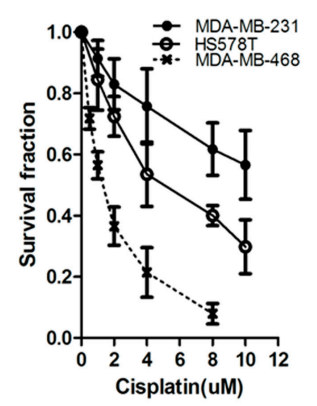

(B)
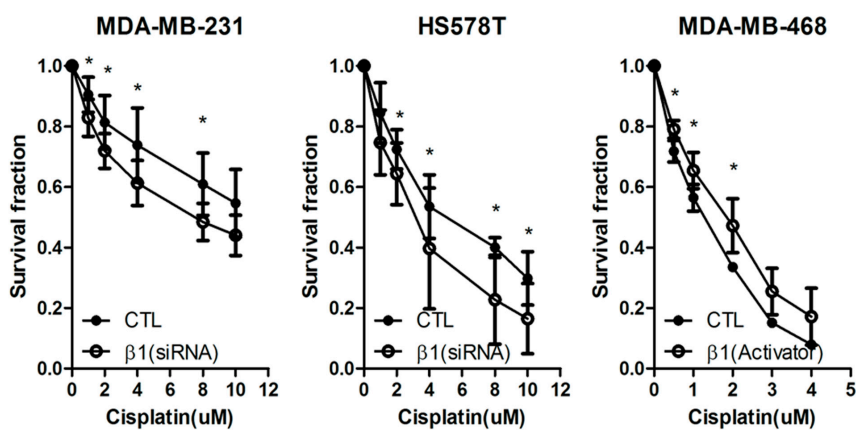

(C)

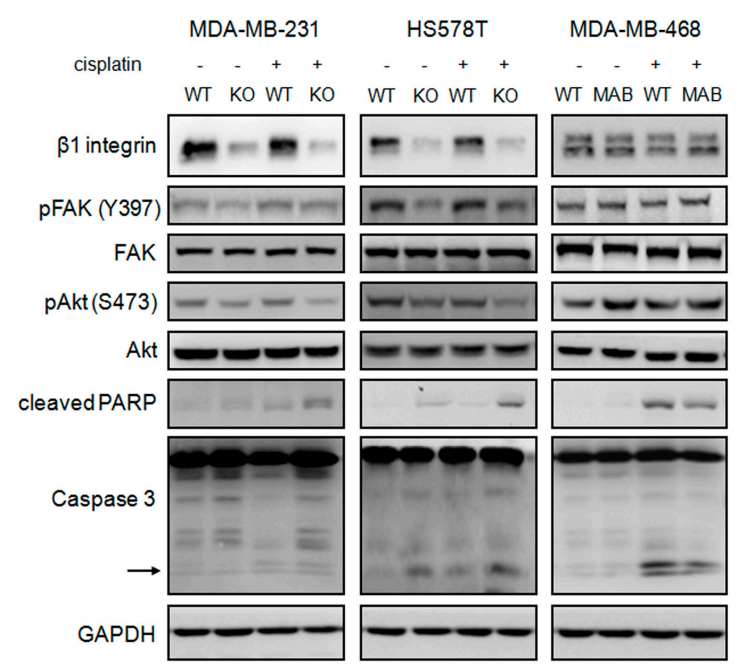

Figure 4. $\beta 1$ integrin regulates cisplatin sensitivity in TNBC cells. (A) 3-(4,5-Dimethylthiazol-2-yl)2,5-Diphenyltetrazolium bromide (MTT) assay showed the cisplatin sensitivity in parental MDA-MB-231, HS578T, and MDA-MB-468 cells; (B) MDA-MB-231 and HS578T cells were transfected with control and $\beta 1$ integrin siRNA for $24 \mathrm{~h}$, and MDA-MB-468 cell was treated with IgG control and $\beta 1$ integrin activator for $6 \mathrm{~h}$. After silencing or activating the $\beta 1$ integrin, cells were treated with different doses of cisplatin. MTT assay showed that the $\beta 1$ integrin silencing enhanced the toxic effect of cisplatin in MDA-MB-231 and HS578T cells, whereas $\beta 1$ integrin activation inhibited the toxic effect of cisplatin in MDA-MB-468 cells. Values are represented as mean \pm SD in at least three independent experiments. Statistically significant data are indicated by * for significant at $p<0.05$; (C) Silencing or activating of $\beta 1$ integrin regulated TNBC cell death through apoptotic pathway. Cell lysates were immunoblotted by anti- $\beta 1$ integrin, anti-cleaved PARP, and anti-Caspase3. GAPDH was used as a loading control. Data were collected in at least three independent experiments. 


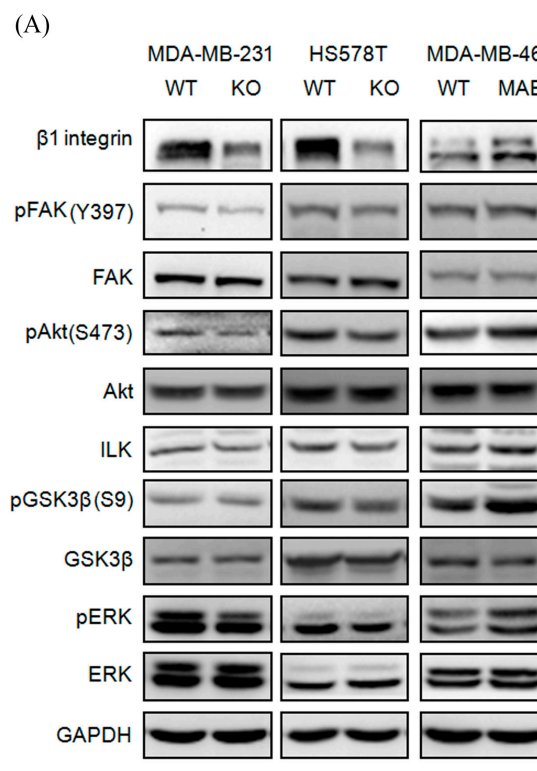

(B)

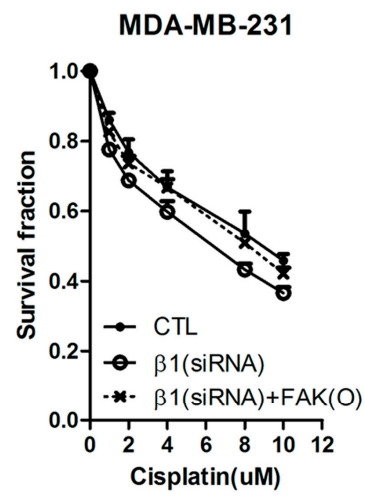

(C)

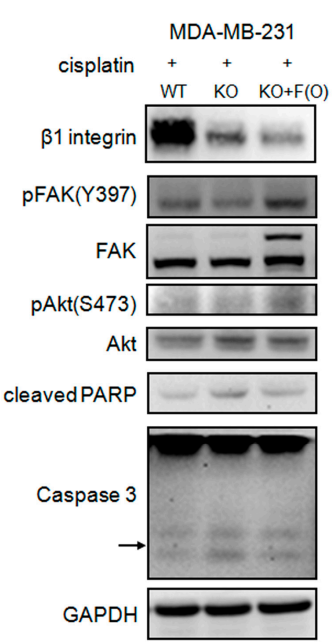

Figure 5. $\beta 1$ integrin modulates FAK-mediated drug sensitivity and cell survival. (A) MDA-MB-231 and HS578T cells were transfected with control and $\beta 1$ integrin siRNA for $24 \mathrm{~h}$ and MDA-MB-468 cell was treated with IgG control and $\beta 1$ integrin activator for $6 \mathrm{~h}$. Cell lysates were immunoblotted by anti- $\beta 1$ integrin, anti-FAK, anti-pFAK (Y397), anti-Akt, anti-pAkt (s473), anti-ERK, anti-pERK, anti-ILK, anti-GSK3 $\beta$, and anti-p-GSK3 $\beta$ (ser9), GAPDH was used as a loading control. Data were collected in at least three independent experiments; (B) MTT assay showed that overexpression of FAK can overcome the cisplatin-mediating cytotoxic effect in $\beta 1$ integrin defects cells; (C) Western blot data showed the enhanced of cytotoxicity of cisplatin in $\beta 1$ integrin silencing $(\mathrm{KO})$ cells were restored by overexpression of FAK $(\mathrm{KO}+\mathrm{F}(\mathrm{O}))$. Cell lysates were immunoblotted by anti- $\beta 1$ integrin, anti-pFAK, anti-FAK, anti-pAkt, anti-Akt, anti-cleaved PARP, and anti-Caspase3. GAPDH was used as a loading control. Data were collected in at least three independent experiments.

\subsection{Relationships Between $\beta 1$ Integrin and Clinicopathological Parameters}

High expression of $\beta 1$ integrin has been reported in many cancer types but is still unclear in TNBC. In order to confirm our in vitro data, immunohistochemical staining was used to investigate the relationships between $\beta 1$ integrin and other clinicopathological parameters in biopsy specimens from 67 TNBC patients. The patients had an average age of $51 \pm 10$ years (range 32-81 years) and an average tumor size of $2.5 \pm 1.5 \mathrm{~cm}$ (range $0.13-7.5 \mathrm{~cm}$ ). Figure 6A shows the TNBC patients with low expression ((a) and (c) respectively) and high expression ((b) and (d) respectively) of $\beta 1$ integrin and 
FAK. Consistent with the in vitro data, there was a positive correlation between $\beta 1$ integrin and FAK (Table 1). Table 2 indicates that $\beta 1$ integrin was significantly associated with metastasis, recurrence, and death $(p=0.039,0.038$, and 0.004 respectively).

(A)
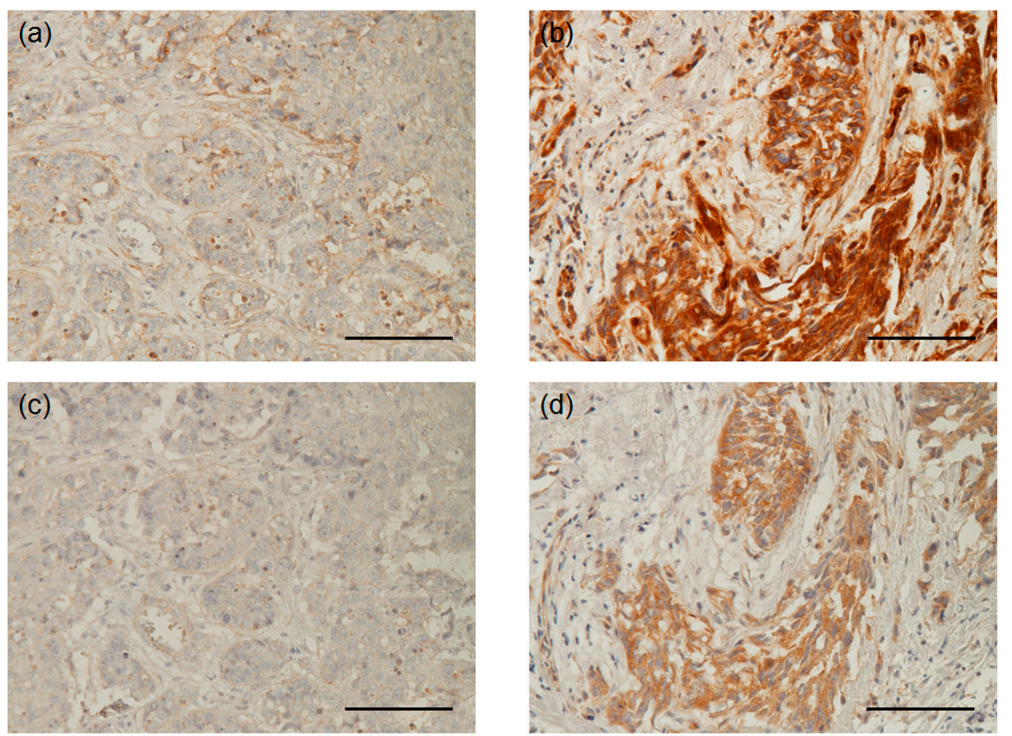

(B)

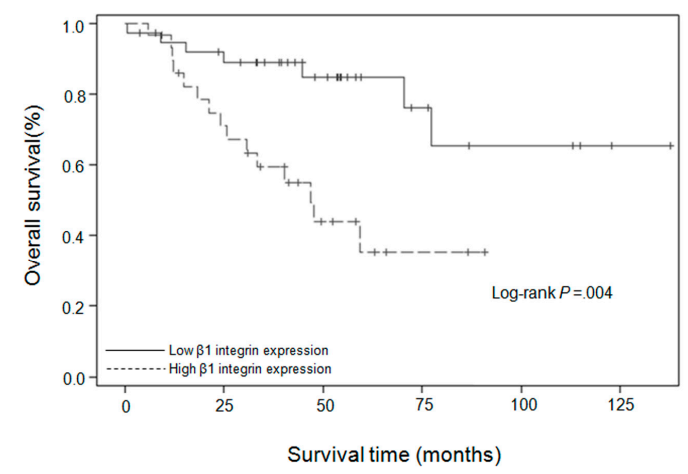

Figure 6. Evaluation of $\beta 1$ integrin as a prognosis marker in TNBC patients. (A) Representative immunostaining results for expressions of $\beta 1$ integrin and FAK in TNBC tissues (original magnification: $\times 200$, scale bar: $100 \mu \mathrm{m})$. Immunoreactivity of $\beta 1$ integrin and FAK were classified as negative ((a) and (c), respectively) or positive ((b) and (d), respectively) according to staining observed in the cell membrane and cytoplasm; (B) Kaplan-Meier survival curves for TNBC patients. Survival was significantly associated with $\beta 1$ integrin expression.

Table 1. Association of $\beta 1$ integrin and FAK expressions in breast tumor tissues.

\begin{tabular}{lcccc}
\hline \multirow{2}{*}{ Protein Expression } & \multicolumn{2}{c}{$\beta 1$ Integrin, $\boldsymbol{n}$ (\%) } & \multirow{2}{*}{$\boldsymbol{p}$-Value } \\
\cline { 3 - 4 } & High & $22(32.83)$ & $19(28.36)$ & \\
\hline FAK, $n(\%)$ & Low & $7(10.45)$ & $19(28.36)$ & $p=0.031$ \\
\hline
\end{tabular}


Table 2. Relationship between $\beta 1$ integrin as a prognostic and predictive marker in triple negative breast cancer expression and clinicopathological characteristics of TNBC patients $(n=67)$.

\begin{tabular}{|c|c|c|c|c|}
\hline \multirow{2}{*}{ Parameters } & \multirow{2}{*}{$n$} & \multicolumn{2}{|c|}{$\beta 1$ Integrin, $n(\%)$} & \multirow{2}{*}{$p$-Value } \\
\hline & & Low & High & \\
\hline Total & 67 & $38(56.72)$ & $29(43.28)$ & \\
\hline Age, $n(\%)$ & & & & 0.0878 \\
\hline$\leq 40$ years & 57 & $35(92.11)$ & $22(75.86)$ & \\
\hline$>40$ years & 10 & $3(7.89)$ & $7(24.14)$ & \\
\hline Size, $n(\%)$ & & & & 0.4753 \\
\hline$\leq 2.0 \mathrm{~cm}$ & 24 & $15(39.47)$ & $9(31.03)$ & \\
\hline$>2.0 \mathrm{~cm}$ & 43 & $23(60.53)$ & $20(68.97)$ & \\
\hline Grade, $n(\%)$ & & & & 0.7530 \\
\hline $\mathrm{I} / \mathrm{II}$ & 24 & $13(34.21)$ & $11(37.93)$ & \\
\hline III & 43 & $25(65.79)$ & $18(62.07)$ & \\
\hline Tumor stage, $n(\%)$ & & & & 0.2893 \\
\hline $\mathrm{T} 1$ & 28 & $18(47.37)$ & $10(34.48)$ & \\
\hline $\mathrm{T} 2 / \mathrm{T} 3$ & 39 & $20(52.63)$ & $19(65.52)$ & \\
\hline Nodal stage, $n(\%)$ & & & & 0.0958 \\
\hline No & 40 & $26(68.42)$ & $14(48.28)$ & \\
\hline $\mathrm{N} 1 / \mathrm{N} 2 / \mathrm{N} 3$ & 27 & $12(31.58)$ & $15(51.72)$ & \\
\hline Metastatic stage, $n(\%)$ & & & & $0.0389 *$ \\
\hline M0 & 48 & $31(81.58)$ & $17(58.62)$ & \\
\hline M1 & 19 & $7(18.42)$ & $12(41.38)$ & \\
\hline Tumor recurrent, $n(\%)$ & & & & 0.0380 * \\
\hline Absent & 61 & 37 (97.37) & $24(82.76)$ & \\
\hline Present & 6 & $1(2.63)$ & $5(17.24)$ & \\
\hline Survival status, $n(\%)$ & & & & 0.0040 * \\
\hline Survival & 45 & $31(81.58)$ & $14(48.28)$ & \\
\hline Death & 22 & $7(18.42)$ & $15(51.72)$ & \\
\hline
\end{tabular}

Statistical analysis was performed using the Chi-squared test. ${ }^{*}$ Statistically significant $(p<0.05)$.

\subsection{Survival Analysis}

We further investigated whether $\beta 1$ integrin expression was associated with patient survival. The Kaplan-Meier test was used to compare the survival time between patients with high and low $\beta 1$ integrin expression. Figure 6B shows that the average disease-specific survival time (months from time of TNBC diagnosis to time of death due to TNBC) in patients with high $\beta 1$ integrin expression was $47.0 \pm 30.9$ months (range, 0.53-137.7 months), which was significantly lower than that in patients with low $\beta 1$ integrin expression $(p=0.002)$. The univariate analysis (Table 3 ) revealed that overall survival was significantly associated with $\beta 1$ integrin expression $(p=0.0004)$, nodal stage $(p<0.0001)$, metastatic stage ( $p=0.0019)$, and tumor recurrence $(p=0.0436)$. Multivariate Cox regression analysis of $\beta 1$ integrin expression, age, tumor grade, nodal stage, metastatic stage, and tumor recurrence showed that $\beta 1$ integrin expression was a significant independent predictor of overall survival $(p=0.0476)$. Taken together, the experimental data indicate that $\beta 1$ integrin has potential use as biomarker of TNBC survival and as a biomarker of TNBC cell migration, invasion, and drug resistance. 
Table 3. Univariate and multivariate logistic analysis of clinicopathological independent prognostic factors for survival of breast cancer patients $(n=67)$.

\begin{tabular}{|c|c|c|c|c|}
\hline \multirow{2}{*}{ Factors } & \multicolumn{2}{|c|}{ Univariate } & \multicolumn{2}{|c|}{ Multivariate } \\
\hline & HR $(95 \%$ CI) & $p$-Value & $\operatorname{HR}(95 \% \mathrm{CI})$ & $p$-Value \\
\hline$\beta 1$ integrin expression & & 0.0040 * & & 0.0476 * \\
\hline Low & 1.0 & & 1.0 & \\
\hline High & 3.805 (1.533-9.446) & & $2.772(1.011-7.600)$ & \\
\hline Age & & 0.8954 & & 0.9776 \\
\hline$\leq 40$ years & 1.0 & & 1.0 & \\
\hline$>40$ years & $0.921(0.269-3.149)$ & & $0.981(0.254-3.784)$ & \\
\hline Grade & & 0.1240 & & 0.1565 \\
\hline $\mathrm{I} / \mathrm{II}$ & 1.0 & & 1.0 & \\
\hline III & $2.190(0.807-5.947)$ & & $2.286(0.728-7.172)$ & \\
\hline Nodal stage & & $<0.0001 *$ & & 0.0005 * \\
\hline N0 & 1.0 & & 1.0 & \\
\hline $\mathrm{N} 1 / \mathrm{N} 2 / \mathrm{N} 3$ & $12.304(3.634-41.656)$ & & $9.602(2.666-34.586)$ & \\
\hline Metastatic stage & & $0.0019 *$ & & 0.4788 \\
\hline M0 & 1.0 & & 1.0 & \\
\hline M1 & 3.895 (1.653-9.178) & & $1.462(0.511-4.186)$ & \\
\hline Tumor recurrent & & 0.0436 * & & 0.8340 \\
\hline Absent & 1.0 & & 1.0 & \\
\hline Present & 3.077 (1.033-9.165) & & $1.142(0.329-3.969)$ & \\
\hline
\end{tabular}

Statistical analysis was performed using Cox multivariate analysis. ${ }^{*}$ Statistically significant $(p<0.05)$.

\section{Discussion}

High level of $\beta 1$ integrin has been associated with poor outcomes in many types of tumors including colon cancer, pancreatic cancer, lung cancer, ovarian cancer and breast cancer [32]. Previous studies have indicated that the increase of $\beta 1$ integrin and their associated signaling pathways promoted cell proliferation, migration, invasion and survival in leading malignant phenotype formation [32]. $\beta 1$ integrin is a kind of transmembrane receptor that communicates with a large number of downstream signaling molecules including integrin-linked kinase (ILK), Caveolin-1, or FAK to trigger survival pathway [33]. The downstream signaling alterations induced by $\beta 1$ integrin are dependent on different cell types of cancer. For example, $\beta 1$ integrin triggers the activation of FAK in contributing chemoresistance and radioresistance in pancreatic cancer and NSCLC $[34,35]$. Integrin-dependent activation of Wnt/ $\beta$-catenin signaling can promote metastasis in ovarian cancer [36]. $\beta 1$ integrin and ILK can trigger the activation of NF- $\kappa B$ to induce cell motility [14]. Conversely, malignant phenotype of tumor cell was inhibited in $\beta 1$ integrin-depleted cells $[14,37]$. Therefore, these lines suggest that $\beta 1$ integrin could be a prognostic marker of survival and therapeutic target in cancer treatment. Based on cell type dependency, identification of specificity of integrin-mediating downstream signaling in different types of cancer is an important issue for the development of therapeutic strategies and diagnostic tools.

Breast cancer is a heterogeneous disease. Seeking and developing a personalized therapy is an important issue in improving outcomes of clinical patients. Pre-clinical and clinical data have suggested that TNBC could be more sensitive to platinum-based chemotherapy in patients with defective homologous recombination repair. However, several randomized trials in evaluating platinum efficacy indicated conflicting results for long-term outcomes [38]. Therefore, it is worth to identify a predictive gene signature in TNBC treatment response. Previously, such evidence has also supported that increased $\beta 1$ integrin is positively correlative with poor outcome in invasive breast cancer [31]. Interestingly, previous evidence demonstrated that expressions of ER and PR were not correlated with expression of $\beta 1$-integrin in clinical outcomes [39]. Consistent with this finding, 
Klahan et al. colleagues combined microarray data from two databases and suggested that $\beta 1$ integrin is a potential candidate biomarker of TNBC patients [40]. Therefore, we next investigated clarification of the role of $\beta 1$ integrin in TNBC patients. In agreement with these findings, our clinical results also showed that high $\beta 1$ integrin expression had significant high metastatic stage, significant high tumor recurrent rate, and significant low survival rate, compared to patients with low $\beta 1$ integrin expression. In addition, the average disease-specific survival time in patients with high $\beta 1$ integrin expression was significantly lower than that in patients with low $\beta 1$ integrin expression. Our univariate analysis showed the overall survival was also significantly associated with $\beta 1$ integrin expression, nodal stage, metastatic stage and tumor recurrence, and the multivariate Cox regression analysis also showed that $\beta 1$ integrin expression was a significant independent predictor of overall survival. Therefore, our data strongly suggested that $\beta 1$ integrin could be a potential prognostic marker of survival in TNBC patients. Therefore, we next focused on illustrating details of mechanism in $\beta 1$ integrin-mediating malignant phenotype of TNBC.

The dissemination of cancer cells from the primary tumor, and their invasion in and out of blood vessels has been linked to EMT-related processes [41]. Thereby, we firstly tried to validate the role of $\beta 1$ integrin in regulating TNBC cell migration, invasion and EMT. We used the MDA-MB-231, HS578T, and MDA-MB-468 cells as the models in this study. MDA-MB-231 and HS578T cells are classified as mesenchymal-like basal B-subtype and highly invasive whereas MDA-MB-468 cell is categorized as basal A-subtype and weakly invasive [42,43]. Figure 1 shows the western blot results indicating that MDA-MB-231 and HS578T cells had significantly higher $\beta 1$ integrin expression compared to MDA-MB-468 and M10 cells. The MDA-MB-231 and HS578T cells also had higher migration compared to MDA-MB-468 cells (Figure 2). Knockdown of the $\beta 1$ integrin expression in MDA-MB-231 and HS578T cells decreased the migration and invasion abilities, however, activation of the $\beta 1$ integrin in MDA-MB-468 cell could increase the migration and invasion abilities. Besides, the western blot results also indicated that $\beta 1$ integrin regulated several EMT-relative proteins in TNBC cells, including $\beta$-catenin, $\mathrm{N}$-cadherin, E-cadherin and vimentin. This indicated that $\beta 1$ integrin was involved in cell migration and invasion through regulating the expression of EMT-associated proteins in TNBC cells.

Besides, $\beta 1$ integrin is associated with drug resistance in several cancer types [44-46]. For example, Huang et al. provided that blocking of $\beta 1$ integrin could enhance cell response to lapatinib in overexpression of epidermal growth factor receptor breast cancer cells [26]. Park et al. reported that the $\beta 1$ integrin inhibition dramatically increased the radiotherapy efficacy in a xenograft model [31]. Additionally, $\beta 1$ integrin deficiency could attenuate malignant phenotype of bevacizumab-resistant cells [47]. In the present study, our results also demonstrated that $\beta 1$ integrin expression was associated with phosphorylated levels of FAK and AKT. Silencing of $\beta 1$ integrin increased cells response to cisplatin and decreased the activity of FAK and AKT in MDA-MB-231 and HS578T cells. Treatment of $\beta 1$ integrin activator promoted the activity of FAK and AKT in MDA-MB-468 cells. More importantly, overexpression of FAK can reverse AKT activity and overcome the toxic effect of cisplatin in MDA-MB-231 cells, suggesting that FAK-AKT axis plays a role in $\beta 1$ integrin-mediated defense system in counteracting cisplatin-induced apoptosis. It is worth noting that several preclinical trials have supported $\beta 1$ integrin as promising chemotherapeutics in efficiently reducing tumor growth and metastasis in vivo [32]. Our finding, no doubt, provides a prompt therapeutic strategy in the treatment of TNBC.

In summary, we reported that high $\beta 1$ integrin expression is correlated with low survival rates and advanced metastatic status in TNBC patients. $\beta 1$ integrin also plays a regulatory role in TNBC cell migration, invasion, and EMT. Additionally, $\beta 1$ integrin could regulate drug sensitivity in TNBC cells. Taken together, our study clearly indicates that $\beta 1$ integrin could not only be a potential prognostic biomarker in TNBC patients, but targeting $\beta 1$ integrin-FAK-AKT axis could be an effective therapeutic strategy in $\beta 1$ integrin overexpressing TNBC cells as well. It has been showed that the level of $\beta 1$ integrin is strictly regulated by miRNA [48,49]. Hereby, development of $\beta 1$ integrin-associated microRNA may be helpful for therapeutic application in TNBC. 


\section{Materials and Methods}

\subsection{Cell Culture}

TNBC cancer cells (MDA-MB-231, HS578T, MDA-MB-468) (ATCC, Manassas, VA, USA) and H184B5F5/M10 human mammary epithelial cell (BCRC, Hsinchu, Taiwan) were used in this study. Cells were maintained in Dulbecco's modified Eagle's medium (DMEM) and DMEM/F12 medium with $10 \%$ fetal bovine serum (FBS) (Hyclone Laboratories Inc., South Logan, UT, USA) and antibiotics at $37{ }^{\circ} \mathrm{C}$ in a $5 \% \mathrm{CO}_{2}$ atmosphere.

\subsection{Reagents}

Antibodies against $\beta 1$ integrin (\#9699, 1:1000), FAK (\#3285, 1:1000), phospho-FAK(Y397) (\#3283, 1:1000), Akt (\#9272, 1:1000), phospho-Akt (S473) (\#9271, 1:1000), Caspase 3 (\#9662S, 1:1000), cleaved PARP (\#9541, 1:1000), p44/42 MAPK (ERK1/2) (\#9107, 1:1000), phospho-p44/42 MAPK (ERK1/2, Thr 202/Tyr 204) (\#9101, 1:1000), Vimentin (\#5741, 1:1000), N-Cadherin (\#13116, 1:1000), $\beta$-Catenin (\#8480, 1:1000), GAPDH (\#2118, 1:5000) and E-Cadherin (\#3195, 1:1000) were purchased from Cell Signaling Technology (Beverly, MA, USA). Mouse IgG1 negative control $(400102,10 \mu \mathrm{g} / \mathrm{mL})$ was from Biolegend (San Diego, CA, USA). Anti- $\beta 1$ integrin activating antibody (MAB1951Z (P4G11), $10 \mu \mathrm{g} / \mathrm{mL}$ ) was obtained from Millipore Corporation (Temecula, CA, USA).

\subsection{Immunoblots}

Proteins extraction and immunoblotting were performed as previously described [33]. In brief, cells were sonicated in protein lysis buffer $\left(\mathrm{M}-\mathrm{PER}^{\mathrm{TM}}\right.$ mammalian protein extraction buffer, Thermo Scientific, Rockford, IL, USA) and cellular debris was removed by centrifugation. Proteins were loaded on an SDS-polyacrylamide gel and transferred to nitrocellulose, and immunoblotting was performed by using the indicated antibodies.

\section{4. $\beta 1$ Integrin Short Interfering RNA and FAK Plasmid Transfection}

Short interfering RNA (siRNA) for human $\beta 1$ integrin (ITGB1, L-004506-00) and negative control (Lamin A/C, D-001050-01-05) were purchased from Dharmacon (Dharmacon Life Technologies, Cologne, Germany). MDA-MB-231 and HS578T cells were transfected with 100 nM nontargeting and specific siRNA using Lipofectamine 2000 and Opti-MEM medium according to the standard protocol provided by Invitrogen (Carlsbad, CA, USA). Constitutively active EGFP-FAK expression constructs were a gift obtained from Chen Hong-Chen's lab (Graduate Institute of Biomedical Sciences, National Chung Hsing University, Taichung, Taiwan). $\beta 1$ integrin silencing cells were transfected with the appropriate amount of expression construct and control empty vector using Lipofectamine 2000 and Opti-MEM medium as mention earlier.

\subsection{Cell Proliferation Assay}

$1 \times 10^{4}$ cells were plated in each well of a 24-well plate. After treated with different doses of cisplatin, cells were stained with MTT solution (Sigma, St. Louis, MO, USA) and incubated for 1-2 h. Finally, the formazan crystals were solubilized in $200 \mu \mathrm{L}$ DMSO (Sigma, St. Louis, MO, USA) and measured at $560 \mathrm{~nm}$.

\subsection{Cell Wound Scrape Assay}

Cells of each group were cultured in 6-well plates. The confluent cell monolayer was made a wound area by a $200 \mu \mathrm{L}$ pipette tip. Cells were then incubated in culture medium at $37{ }^{\circ} \mathrm{C}$ in a $5 \% \mathrm{CO}_{2}$ incubator for $24 \mathrm{~h}$. Images were captured at 0 and $24 \mathrm{~h}$. The experiments were repeated in triplicate. 


\subsection{Cell Invasion Assay}

Cell invasion assay were performed as previously described [40]. In brief, cells were seeded in the inserts placed in the upper chamber of transwell. $500 \mu \mathrm{L}$ DMEM containing 10\% FBS was plated in the bottom chamber. After $24 \mathrm{~h}$ incubation, cells were rinsed and stained with crystal violet solution (Sigma, St. Louis, MO, USA). The number of invading cells was resulted from triplicate cell invasion assays.

\subsection{Specimens}

Formalin-fixed, paraffin-embedded blocks of tissues from 67 TNBC patients were selected from the Department of Pathology, Kaohsiung Medical University Hospital, Kaohsiung, Taiwan. Institutional Review Board approval for using these human tissues in this study was given by the Research Ethics Committee of the Kaohsiung Medical Hospital (IRB: KMUHIRB-E(II)-20150086) on 22 June 2015.

\subsection{Immunohistochemistry (IHC) Staining}

Blocks of tissue samples embedded in paraffin were sectioned into thicknesses of $4 \mu \mathrm{m}$. The samples were de-paraffinized, rehydrated, and then autoclaved at $121^{\circ} \mathrm{C}$ for $9 \mathrm{~min}$ in $\mathrm{pH} 6.0 \mathrm{DAKO}$ target retrieval solution (DAKO, Carpinteria, CA, USA) to induce antigen retrieval. In each section, endogenous peroxidase was blocked by incubation in 3\% hydrogen peroxide (Sigma, St. Louis, MO, USA) for $10 \mathrm{~min}$. Sections were incubated with $\beta 1$ integrin and FAK (sc-558, Santa Cruz Biotechnology, Inc., Dallas, TX, USA) primary antibodies at room temperature for $1 \mathrm{~h}$. The DAKO REAL Envision Detection kit (DAKO, Carpinteria, CA, USA) was then applied for $1 \mathrm{~h}$. Finally, sections were incubated in 3'3-diaminobenzidine for 5 min, counterstained with Mayer's Hematoxylin, and mounted. Negative controls were prepared by replacing the primary antibodies with non-immune serum.

\subsection{Scoring}

$\beta 1$ integrin expression in different patients was scored according to Yao et al. [39] in which sample was scored based on the intensity of signal $(0,1+, 2+, 3+)$ and the proportion of positive cells $(0 \leq 10 \%$, $1=10 \%-25 \%, 2=25 \%-50 \%, 3 \geq 50 \%$ ). The staining index was calculated as the product of the intensity of signal and the proportion of positive cells. The score of image ranged from 0 to 9 . Score $\leq 4$ was defined as negative/low expression and score $\geq 6$ was indicated as positive/high expression.

\subsection{Statistical Analysis}

Expression of $\beta 1$ integrin in TNBC tissues as determined by immunohistochemical staining was compared and assessed by Chi-square test. To evaluate the use of $\beta 1$ integrin for TNBC prognosis, survival curves were performed by Kaplan-Meier method. A Cox proportional hazards model was used to evaluate univariate comparisons of overall survival with clinicopathologic variables. Two-tailed Student's $t$ test was used to compare the difference of groups. $P$ value less than 0.05 was considered statistically significant. All statistic analyses were performed using SPSS 19.0 software (IBM Corp., Armonk, NY, USA).

Acknowledgments: We acknowledge the support from the following grants: (1) MOHW105-TDU-B-212-134005 from Ministry of Health and Welfare, Taiwan; (2) KMUH104-4P01 from the Kaohsiung Medical University Hospital.

Author Contributions: Chi-Wen Luo and Mei-Ren Pan conceived and designed the experiments; Hsin-Ling Yin and Chun-Chieh Wu performed the experiments; Chih-Hung Lin, Shu-Jyuan Chang, and Hung-Pei Tsai analyzed the data; Chee-Yin Chai and Ming-Feng Hou contributed reagents/materials/analysis tools; Hsin-Ling Yin wrote the paper; Chi-Wen Luo and Mei-Ren Pan helped to complete the manuscript; Wen-Chun Hung as well as all authors read and approved the final manuscript.

Conflicts of Interest: The authors declare no conflict of interest. 


\section{References}

1. O'Reilly, E.A.; Gubbins, L.; Sharma, S.; Tully, R.; Guang, M.H.; Weiner-Gorzel, K.; McCaffrey, J.; Harrison, M.; Furlong, F.; Kell, M.; et al. The fate of chemoresistance in triple negative breast cancer (TNBC). BBA Clin. 2015, 3, 257-275. [CrossRef] [PubMed]

2. Morris, G.J.; Naidu, S.; Topham, A.K.; Guiles, F.; Xu, Y.; McCue, P.; Schwartz, G.F.; Park, P.K.; Rosenberg, A.L.; Brill, K.; et al. Differences in breast carcinoma characteristics in newly diagnosed African-American and Caucasian patients. Cancer 2007, 110, 876-884. [CrossRef] [PubMed]

3. Haffty, B.G.; Yang, Q.; Reiss, M.; Kearney, T.; Higgins, S.A.; Weidhaas, J.; Harris, L.; Hait, W.; Toppmeyer, D. Locoregional relapse and distant metastasis in conservatively managed triple negative early-stage breast cancer. J. Clin. Oncol. 2006, 24, 5652-5657. [CrossRef] [PubMed]

4. Viale, G.; Rotmensz, N.; Maisonneuve, P.; Bottiglieri, L.; Montagna, E.; Luini, A.; Veronesi, P.; Intra, M.; Torrisi, R.; Cardillo, A.; et al. Invasive ductal carcinoma of the breast with the "triple-negative" phenotype: Prognostic implications of EGFR immunoreactivity. Breast Cancer Res. Treat. 2009, 116, 317-328. [CrossRef] [PubMed]

5. Anders, C.K.; Carey, L.A. Biology, metastatic patterns, and treatment of patients with triple-negative breast cancer. Clin. Breast Cancer 2009, 9, S73-S81. [CrossRef] [PubMed]

6. Bonotto, M.; Gerratana, L.; Poletto, E.; Driol, P.; Giangreco, M.; Russo, S.; Minisini, A.M.; Andreetta, C.; Mansutti, M.; Pisa, F.E.; et al. Measures of outcome in metastatic breast cancer: Insights from a real-world scenario. Oncologist 2014, 19, 608-615. [CrossRef] [PubMed]

7. Dent, R.; Trudeau, M.; Pritchard, K.I.; Hanna, W.M.; Kahn, H.K.; Sawka, C.A.; Lickley, L.A.; Rawlinson, E.; Sun, P.; Narod, S.A. Triple-negative breast cancer: Clinical features and patterns of recurrence. Clin. Cancer Res. 2007, 13, 4429-4434. [CrossRef] [PubMed]

8. Yamaguchi, H.; Wyckoff, J.; Condeelis, J. Cell migration in tumors. Curr. Opin. Cell Biol. 2005, 17, 559-564. [CrossRef] [PubMed]

9. Gilcrease, M.Z. Integrin signaling in epithelial cells. Cancer Lett. 2007, 247, 1-25. [CrossRef] [PubMed]

10. Esposito, M.; Kang, Y. Targeting tumor-stromal interactions in bone metastasis. Pharmacol. Ther. 2014, 141, 222-233. [CrossRef] [PubMed]

11. Naci, D.; Vuori, K.; Aoudjit, F. $\alpha 2 \beta 1$ integrin in cancer development and chemoresistance. Semin. Cancer Biol. 2015, 35, 145-153. [CrossRef] [PubMed]

12. Scales, T.M.; Parsons, M. Spatial and temporal regulation of integrin signalling during cell migration. Curr. Opin. Cell Biol. 2011, 23, 562-568. [CrossRef] [PubMed]

13. Dos Santos, P.B.; Zanetti, J.S.; Ribeiro-Silva, A.; Beltrao, E.I. $\beta 1$ integrin predicts survival in breast cancer: A clinicopathological and immunohistochemical study. Diagn. Pathol. 2012, 7, 1. [CrossRef] [PubMed]

14. Blandin, A.F.; Renner, G.; Lehmann, M.; Lelong-Rebel, I.; Martin, S.; Dontenwill, M. $\beta 1$ Integrins as therapeutic targets to disrupt hallmarks of cancer. Front. Pharmacol. 2015, 6, 279. [CrossRef]

15. Kenny, P.A.; Lee, G.Y.; Myers, C.A.; Neve, R.M.; Semeiks, J.R.; Spellman, P.T.; Lorenz, K.; Lee, E.H.; Barcellos-Hoff, M.H.; Petersen, O.W.; et al. The morphologies of breast cancer cell lines in three-dimensional assays correlate with their profiles of gene expression. Mol. Oncol. 2007, 1, 84-96. [CrossRef] [PubMed]

16. Cheng, Y.J.; Zhu, Z.X.; Zhou, J.S.; Hu, Z.Q.; Zhang, J.P.; Cai, Q.P.; Wang, L.H. Silencing profilin-1 inhibits gastric cancer progression via integrin $\beta 1 /$ focal adhesion kinase pathway modulation. World J. Gastroenterol. 2015, 21, 2323-2335. [CrossRef] [PubMed]

17. Guo, G.; Gong, K.; Wohlfeld, B.; Hatanpaa, K.J.; Zhao, D.; Habib, A.A. Ligand-Independent EGFR Signaling. Cancer Res. 2015, 75, 3436-3441. [CrossRef] [PubMed]

18. Hu, C.; Ni, Z.; Li, B.S.; Yong, X.; Yang, X.; Zhang, J.W.; Zhang, D.; Qin, Y.; Jie, M.M.; Dong, H.; et al. hTERT promotes the invasion of gastric cancer cells by enhancing FOXO3a ubiquitination and subsequent ITGB1 upregulation. Gut 2015. [CrossRef]

19. Li, N.; Zhang, Y.; Naylor, M.J.; Schatzmann, F.; Maurer, F.; Wintermantel, T.; Schuetz, G.; Mueller, U.; Streuli, C.H.; Hynes, N.E. $\beta 1$ integrins regulate mammary gland proliferation and maintain the integrity of mammary alveoli. EMBO J. 2005, 24, 1942-1953. [CrossRef] [PubMed]

20. Li, X.; Ishihara, S.; Yasuda, M.; Nishioka, T.; Mizutani, T.; Ishikawa, M.; Kawabata, K.; Shirato, H.; Haga, H. Lung cancer cells that survive ionizing radiation show increased integrin $\alpha 2 \beta 1$ - and EGFR-dependent invasiveness. PLoS ONE 2013, 8, e70905. [CrossRef] [PubMed] 
21. Mai, A.; Muharram, G.; Barrow-McGee, R.; Baghirov, H.; Rantala, J.; Kermorgant, S.; Ivaska, J. Distinct c-Met activation mechanisms induce cell rounding or invasion through pathways involving integrins, RhoA and HIP1. J. Cell Sci. 2014, 127, 1938-1952. [CrossRef] [PubMed]

22. Williams, K.C.; Coppolino, M.G. SNARE-dependent interaction of Src, EGFR and $\beta 1$ integrin regulates invadopodia formation and tumor cell invasion. J. Cell Sci. 2014, 127, 1712-1725. [CrossRef] [PubMed]

23. Zhou, P.; Erfani, S.; Liu, Z.; Jia, C.; Chen, Y.; Xu, B.; Deng, X.; Alfaro, J.E.; Chen, L.; Napier, D.; et al. CD151- $\alpha 3 \beta 1$ integrin complexes are prognostic markers of glioblastoma and cooperate with EGFR to drive tumor cell motility and invasion. Oncotarget 2015, 6, 29675-29693. [PubMed]

24. Fedorenko, I.V.; Abel, E.V.; Koomen, J.M.; Fang, B.; Wood, E.R.; Chen, Y.A.; Fisher, K.J.; Iyengar, S.; Dahlman, K.B.; Wargo, J.A.; et al. Fibronectin induction abrogates the BRAF inhibitor response of BRAF V600E/PTEN-null melanoma cells. Oncogene 2016, 35, 1225-1235. [CrossRef] [PubMed]

25. Hirata, E.; Girotti, M.R.; Viros, A.; Hooper, S.; Spencer-Dene, B.; Matsuda, M.; Larkin, J.; Marais, R.; Sahai, E. Intravital imaging reveals how BRAF inhibition generates drug-tolerant microenvironments with high integrin $\beta 1 / F A K$ signaling. Cancer Cell 2015, 27, 574-588. [CrossRef] [PubMed]

26. Huang, C.; Park, C.C.; Hilsenbeck, S.G.; Ward, R.; Rimawi, M.F.; Wang, Y.C.; Shou, J.; Bissell, M.J.; Osborne, C.K.; Schiff, R. $\beta 1$ integrin mediates an alternative survival pathway in breast cancer cells resistant to lapatinib. Breast Cancer Res. 2011, 13, R84. [CrossRef] [PubMed]

27. McGrail, D.J.; Khambhati, N.N.; Qi, M.X.; Patel, K.S.; Ravikumar, N.; Brandenburg, C.P.; Dawson, M.R. Alterations in ovarian cancer cell adhesion drive taxol resistance by increasing microtubule dynamics in a FAK-dependent manner. Sci. Rep. 2015, 5, 9529. [CrossRef] [PubMed]

28. Yuan, J.; Liu, M.; Yang, L.; Tu, G.; Zhu, Q.; Chen, M.; Cheng, H.; Luo, H.; Fu, W.; Li, Z.; et al. Acquisition of epithelial-mesenchymal transition phenotype in the tamoxifen-resistant breast cancer cell: A new role for $\mathrm{G}$ protein-coupled estrogen receptor in mediating tamoxifen resistance through cancer-associated fibroblast-derived fibronectin and $\beta 1$-integrin signaling pathway in tumor cells. Breast Cancer Res. 2015, 17, 69. [CrossRef] [PubMed]

29. Bhaskar, V.; Zhang, D.; Fox, M.; Seto, P.; Wong, M.H.; Wales, P.E.; Powers, D.; Chao, D.T.; Dubridge, R.B.; Ramakrishnan, V. A function blocking anti-mouse integrin $\alpha 5 \beta 1$ antibody inhibits angiogenesis and impedes tumor growth in vivo. J. Transl. Med. 2007, 5, 61. [CrossRef] [PubMed]

30. Ricart, A.D.; Tolcher, A.W.; Liu, G.; Holen, K.; Schwartz, G.; Albertini, M.; Weiss, G.; Yazji, S.; Ng, C.; Wilding, G. Volociximab, a chimeric monoclonal antibody that specifically binds $\alpha 5 \beta 1$ integrin: A phase I, pharmacokinetic, and biological correlative study. Clin. Cancer Res. 2008, 14, 7924-7929. [CrossRef] [PubMed]

31. Park, C.C.; Zhang, H.J.; Yao, E.S.; Park, C.J.; Bissell, M.J. $\beta 1$ integrin inhibition dramatically enhances radiotherapy efficacy in human breast cancer xenografts. Cancer Res. 2008, 68, 4398-4405. [CrossRef] [PubMed]

32. Desgrosellier, J.S.; Cheresh, D.A. Integrins in cancer: Biological implications and therapeutic opportunities. Nat. Rev. Cancer 2010, 10, 9-22. [CrossRef] [PubMed]

33. Luo, C.W.; Wu, C.C.; Ch'ang, H.J. Radiation sensitization of tumor cells induced by shear stress: The roles of integrins and FAK. Biochim. Biophys. Acta 2014, 1843, 2129-2137. [CrossRef] [PubMed]

34. Ju, L.; Zhou, C. Integrin $\beta 1$ enhances the epithelial-mesenchymal transition in association with gefitinib resistance of non-small cell lung cancer. Cancer Biomark. 2013, 13, 329-336. [PubMed]

35. Mantoni, T.S.; Lunardi, S.; Al-Assar, O.; Masamune, A.; Brunner, T.B. Pancreatic stellate cells radioprotect pancreatic cancer cells through $\beta 1$-integrin signaling. Cancer Res. 2011, 71, 3453-3458. [CrossRef] [PubMed]

36. Burkhalter, R.J.; Symowicz, J.; Hudson, L.G.; Gottardi, C.J.; Stack, M.S. Integrin regulation of $\beta$-catenin signaling in ovarian carcinoma. J. Biol. Chem. 2011, 286, 23467-23475. [CrossRef] [PubMed]

37. Barkan, D.; Chambers, A.F. $\beta 1$-integrin: A potential therapeutic target in the battle against cancer recurrence. Clin. Cancer Res. 2011, 17, 7219-7223. [CrossRef] [PubMed]

38. Gerratana, L.; Fanotto, V.; Pelizzari, G.; Agostinetto, E.; Puglisi, F. Do platinum salts fit all triple negative breast cancers? Cancer Treat. Rev. 2016, 48, 34-41. [CrossRef] [PubMed]

39. Yao, E.S.; Zhang, H.; Chen, Y.Y.; Lee, B.; Chew, K.; Moore, D.; Park, C. Increased $\beta 1$ integrin is associated with decreased survival in invasive breast cancer. Cancer Res. 2007, 67, 659-664. [CrossRef] [PubMed] 
40. Klahan, S.; Huang, W.C.; Chang, C.M.; Wong, H.S.; Huang, C.C.; Wu, M.S.; Lin, Y.C.; Lu, H.F.; Hou, M.F.; Chang, W.C. Gene expression profiling combined with functional analysis identify integrin $\beta 1$ (ITGB1) as a potential prognosis biomarker in triple negative breast cancer. Pharmacol. Res. 2016, 104, 31-37. [CrossRef] [PubMed]

41. Bulfoni, M.; Gerratana, L.; del Ben, F.; Marzinotto, S.; Sorrentino, M.; Turetta, M.; Scoles, G.; Toffoletto, B.; Isola, M.; Beltrami, C.A.; et al. In patients with metastatic breast cancer the identification of circulating tumor cells in epithelial-to-mesenchymal transition is associated with a poor prognosis. Breast Cancer Res. 2016, 18, 30. [CrossRef] [PubMed]

42. Neve, R.M.; Chin, K.; Fridlyand, J.; Yeh, J.; Baehner, F.L.; Fevr, T.; Clark, L.; Bayani, N.; Coppe, J.P.; Tong, F.; et al. A collection of breast cancer cell lines for the study of functionally distinct cancer subtypes. Cancer Cell 2006, 10, 515-527. [CrossRef] [PubMed]

43. Zajchowski, D.A.; Bartholdi, M.F.; Gong, Y.; Webster, L.; Liu, H.L.; Munishkin, A.; Beauheim, C.; Harvey, S.; Ethier, S.P.; Johnson, P.H. Identification of gene expression profiles that predict the aggressive behavior of breast cancer cells. Cancer Res. 2001, 61, 5168-5178. [PubMed]

44. Aoudjit, F.; Vuori, K. Integrin signaling inhibits paclitaxel-induced apoptosis in breast cancer cells. Oncogene 2001, 20, 4995-5004. [CrossRef] [PubMed]

45. Damiano, J.S.; Cress, A.E.; Hazlehurst, L.A.; Shtil, A.A.; Dalton, W.S. Cell adhesion mediated drug resistance (CAM-DR): Role of integrins and resistance to apoptosis in human myeloma cell lines. Blood 1999, 93, 1658-1667. [PubMed]

46. Hodkinson, P.S.; Mackinnon, A.C.; Sethi, T. Extracellular matrix regulation of drug resistance in small-cell lung cancer. Int. J. Radiat. Biol. 2007, 83, 733-741. [CrossRef] [PubMed]

47. Jahangiri, A.; Aghi, M.K.; Carbonell, W.S. $\beta 1$ integrin: Critical path to antiangiogenic therapy resistance and beyond. Cancer Res. 2014, 74, 3-7. [CrossRef] [PubMed]

48. Kato, T.; Enomoto, A.; Watanabe, T.; Haga, H.; Ishida, S.; Kondo, Y.; Furukawa, K.; Urano, T.; Mii, S.; Weng, L.; et al. TRIM27/MRTF-B-dependent integrin $\beta 1$ expression defines leading cells in cancer cell collectives. Cell Rep. 2014, 7, 1156-1167. [CrossRef] [PubMed]

49. Kurozumi, A.; Goto, Y.; Matsushita, R.; Fukumoto, I.; Kato, M.; Nishikawa, R.; Sakamoto, S.; Enokida, H.; Nakagawa, M.; Ichikawa, T.; et al. Tumor-suppressive microRNA-223 inhibits cancer cell migration and invasion by targeting ITGA3/ITGB1 signaling in prostate cancer. Cancer Sci. 2016, 107, 84-94. [CrossRef] [PubMed]

(C) 2016 by the authors; licensee MDPI, Basel, Switzerland. This article is an open access article distributed under the terms and conditions of the Creative Commons Attribution (CC-BY) license (http://creativecommons.org/licenses/by/4.0/). 